\title{
Índice de Materias del Volumen 53, Números 1 y 2
}

A

Abono

Acústico

Áfido verde

Agricultura orgánica

Albahaca dulce

Angiosperma primitiva

Antagonismo

Apareamiento

Árbol endémico raro

Árboles maderables

\section{B}

Bat list

Bentazon

Bosque bajo subtropical

Bosque deciduo bajo

Bosque de pino-encino

Bosque de tierras bajas

Bosque muy húmedo montano 109

Bosque nublado

Bosque seco tropical

Bosque secundario

Brazilian brown bat

C

Cambio climático global

Caracara cheriway

Caracara común

Cautiverio

Chiroptera

Clethodim

Clorotalonil

Coffee habitat

Colibrí esmeralda

Common names

Compost

Conservación

Conservación biológica

Control biológico

Control de malezas

Cópula

Cortejo

Costa Rica

Cynomops mexicanus
D

$\begin{aligned} 17 & \text { Deforestación tropical } \\ 30 & \text { Deformación del pico } \\ 7 & \text { Detección acústica } \\ 17 & \text { Distribución } \\ 17 & \text { Dremel } \\ 81 & \text { Duraznero } \\ 57 & \\ 73 & \text { E }\end{aligned}$

81 EBDCs

81 Ecolocación

Efectividad de herbicida

Entomophthorales

77

57

109

38

38

81

109

38

109

77

109

69

69

69,73

30

57

7

77

38

81

17

1

95

7,17

57

73

73

95

30
Eptésico de Brasil

Eptesicus brasiliensis

Eptésico de Brasil

Especies taladas

Espectograma

Eumops underwoodi

Evolución

Explotación legal de huevos

de tortuga

$\mathbf{F}$

Fertilizante

Formulaciones

Fragmentos de bosque

Fungicida

G

Gramíneas

H

Hábitat de café

Haptanthus hazlettii

Herbicida

Herbicida de contacto

Herbicida selectivo

Honduras 30, 38, 69, 73, 77, 81,

109

Hongos entomopatógenos

I

Incertidumbre climática

Índice de valor de importancia

30

7
Ingrediente activo

57

81 Ingrediente inerte

57

$30 \quad \mathbf{L}$

30 Lasirius cinereus 30

69 Lepidochelys olivacea 95

7 Lista de murciélagos 77

Lluvia horizontal 109

Lowland forest

81

7

$30 \quad \mathbf{M}$

57 Manejo de vida silvestre 95

7 Medios acústicos $\quad 30$

77 Microorganismo 17

77 Mildiú lanoso 17

77 Murciélago 1, 30

$81 \quad$ Myotis keaysi 30

77 Myzus persicae 7

$1 \mathbf{N}$

Nombres científicos $\quad 81$

$95 \quad$ Nombres comunes 81

Noteworthy record $\quad 77$

170

57 Ocymum basilicum 17

38 Oomiceto 17

$\mathbf{P}$

Papa 7

$57 \quad$ Perimyotis subflavus $\quad 30$

Peronospora belbahrii $\quad 17$

Playas de anidación 95

77 Phytophthora infestans 7

81 Precipitación oculta 109

57 Precipitación normal 109

57 Primitive angiosperm 81

57 Puma yagouaroundi 73

$\mathbf{R}$

7 Rapaces 69

Rare endemic tree 81

Recinto 73

109 Refugio Nacional de Vida Silvestre

Ostional

95 
Índice de Materias del Volumen 53, Número 1 y 2

Reseña de libro
Reserva Biológica Uyuca

S

Scientific names

Servicios ecosistémicos

Species harvested

Spectrogram

Suplemento nutricional

$\begin{aligned} 1 & \text { T } \\ 109 & \text { Timber species } \\ & \text { Tizón tardío } \\ & \text { Tortuga lora } \\ 81 & \text { Tortugas marinas } \\ 109 & \text { Tropical deforestation } \\ 81 & \\ 77 & \text { V } \\ 17 & \text { Vespertilionidae } \\ & \text { Volumen de madera extre }\end{aligned}$

Volumen de madera extraído
W

81 Wood volume removed

7

$95 \quad \mathbf{Y}$

95 Yaguarundí

81

$\mathbf{Z}$

77

Zoológico Rosy Walther $\quad 69,73$

81

73

81 